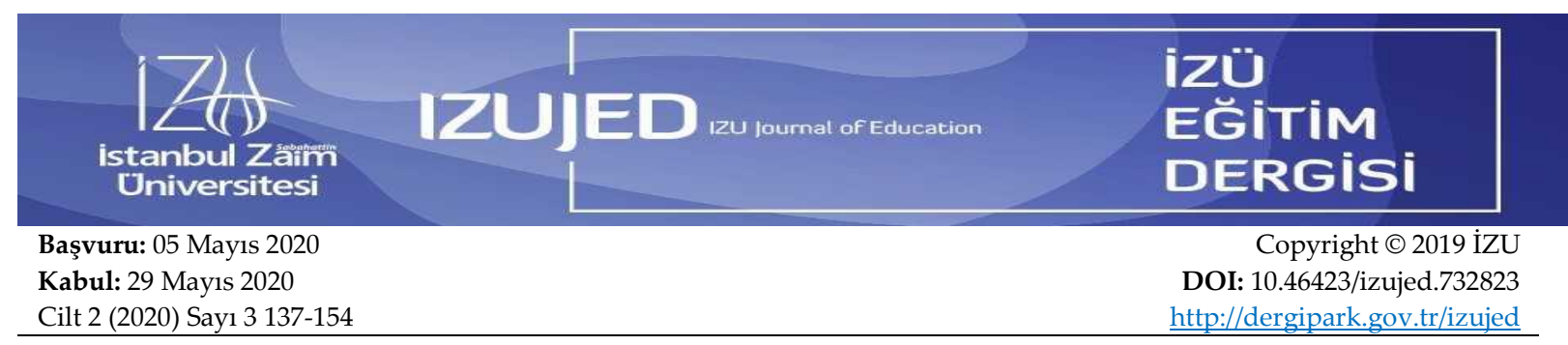

\title{
Öğrencilerin Başarısına ve Öğrenmesine Yönelik Öğretmen Görüşleri Ölçeği (ÖBÖY-ÖGÖ)
}

\author{
Kamil Arif KIRKIÇ¹
}

\author{
Emin AYDIN ${ }^{2}$
}

Ömer YAHŞİ

\begin{abstract}
Öz
Gerçekleştirilen bu çalışma ile öğrencilerin başarısı ve öğrenmesine yönelik öğretmen görüşleri ölçeğinin geliştirilmesi amaçlanmıştır. Çalışmaya öğretmenlik deneyimleri 1-40 yıl arasında değişen toplam 636 ilkokul, ortaokul ve lise öğretmeni katılmıştır. Çalışmanın ön-deneme aşamasında 37; açıklayıcı faktör analizin ve doğrulayıcı faktör analizi aşamalarında ise, sırasıyla, 285 ve 314 öğretmen ile çalışılmıştır. Uzman görüşü ile sağlanan kapsam geçerliliği sonrası yapılan faktör analizi sonucu 11 maddeli dört faktörlü AFA ile ortaya çıkmıştır. Ölçek için KMO (Kaiser-Meyer-Olkin) değeri .719, Barlett's Sphericity testi $\chi^{2}=20320,565, p=.000$ olarak belirlenmiştir. Dört faktörlü yapının 1 . Faktörü ölçek varyansının \%190,132; 2. Faktörü \%16,805; 3. \%15,767 ve 4. Faktörü de \%15,452'sini açıklamaktadır. Ölçeğe ait dört faktörün ölçeğin varyansının \%67,155'ini açıkladığı görülmektedir. Ölçekte bulunan 11 maddenin faktör ortak varyans değerlerinin 0,467- 0,908; madde faktör yüklerinin ise 0,635-0,941 arasında değiştiği belirlenmiştir. Ortaya çıkan modelin DFA sonucunda elde edilen uyum indekslerinin modelin doğrulanması için yeterli olduğu görülmektedir. Ölçek Cronbach Alfa iç tutarlılık katsayısının 0,76 olduğu görülmektedir. Bu sonuçlar değerlendirildiğinde öğrencilerin başarısı ve öğrenmesine yönelik öğretmen görüşleri ölçeğinin güvenilir ve geçerli bir ölçme aracı olduğu sonucuna ulaşılabilir.
\end{abstract}

Anahtar Kelimeler: Ölçek geliştirme; Öğretmen Görüşü Ölçeği, Başarı, Öğrenme, Faktör analizi

\section{Teachers' Opinions Scale about Students' Achievement and Learning (TOS-ASAL)}

\begin{abstract}
With this study, it was aimed to develop the teacher opinions scale about students' achievement and learning. A total of 636 primary, secondary and high school teachers whose teaching experience varied between 1-40 years participated in the study. At the pilot stage of the study 37; in the stages of exploratory factor analysis and confirmatory factor analysis, 285 and 314 teachers participated respectively. As a result of the factor analysis made after the scope validity provided by the expert opinion, the 11-items with four-factor AFA emerged. KMO (Kaiser-Meyer-Olkin) value for the scale is .719 , Barlett's Sphericity test $\chi^{2}=20320,565, p=.0 \quad 00$. The first factor of the four-factor structure was is $19.132 \%$ of the scale variance; 2 nd Factor $160,805 \%$; 3 rd $150,767 \%$ and Factor 4 explains $150,452 \%$. It is seen that four factors belonging to the scale explains $670,155 \%$ of the variance of the scale. Factor common variance values of 11 items in the scale are 467-, 908; item factor loads are determined to vary
\end{abstract}

1 Dr., İstanbul Sabahattin Zaim Üniversitesi, Eğitim Fakültesi, İstanbul, Türkiye ORCID: 000-0002-8902437X kamil.kirkic@izu.edu.tr;

${ }^{2}$ Sorumlu Yazar: Prof. Dr. Atatürk Eğitim Fakültesi, İstanbul, Türkiye ORCID: 0000-0003-4298-2623 eaydin@marmara.edu.tr

3 Milli Eğitim Bakanlığı, İzmir İl Milli Eğitim Müdürlüğü, İzmir, Türkiye ORCID: 0000-0003-3872-6010, oyahsi@gmail.com

Atıf: Kırkıç, K. A., Aydın, E. ve Yahşi, Ö. (2020). Öğrencilerin Başarısına ve Öğrenmesine Yönelik Öğretmen Görüşleri Ölçeği (ÖBÖY-ÖGÖ). İZÜ Ĕ̆itim Dergisi, 2 (3) 137-154. DOI: 10.46423/izujed.732823 
between 635 and 941 . The fit indices of the resulting model are sufficient to confirm the model. Scale Cronbach Alpha internal consistency coefficient appears to be .76. When these results are evaluated, it can be concluded that the teacher beliefs scale for about students' success and learning is a reliable and valid measurement tool.

Keywords: Scale Development; Teacher's Opinion Scale, Achievement, Learning, Factor Analysis

\section{Extended Abstract}

\section{Introduction}

Teachers specify various approaches, sets of values (paradigms) when performing their job and labor to realize the learning process with certain appropriate methods and techniques (Biçer, Er \& Özel, 2013; Demir \& Akınoğlu, 2010). The approach and set of values adopted and the appropriate methods techniques used by the teachers are related to their beliefs opinions regarding learning (Borko \& Putnam, 1996; Demir \& Akınoğlu, 2010; Demir, 2013; Ediger, 2000; Hashweh,1996). In addition, teachers' expectations from their students are directly related to the success levels of students (Gales \& Yan, 2001; Sah \& Shah, 2020; Love, 2002; Muijs \& Reynolds, 2002; Rashidi \& Mughadam, 2014; Rosenthall \& Jacobson, 1968, Akt. Yildıran, 2006). Changes in the opinions and philosophies of teachers may lead to differentiations in the methods and techniques they use during the teaching process (Doğanay, 2011; Golombek, 1998; Pedersen \& Liu, 2003). Though there are studies in the literature that state activities and applications in class performed by teachers are not related to teacher opinions, there are also some studies that there is a significant relationship between teachers' opinions and their teaching behaviors (Abu Radwan, 2019; Beck et al., 2000).

If teachers' expectations significantly influence the academic achievements of their students (Yildiran, 2006), their opinions about the student achievement and learning, which influence their preferences on expectations, carry great importance in terms of achieving the desired results of education. Determining teacher opinions about learning and student achievement is also deemed important with regards to increasing students' learning levels. Thus, the aim of this study was to develop a measurement tool that can measure teacher opinions on students' achievement and learning with high validity and reliability.

\section{Method}

Survey model is chosen as the study model beceause it aims to determine the current situation. 37 teachers working in a school participated voluntarily in the pilot stage. In the exploratory factor analysis stage, data gathering was conducted with the voluntary participation of 285 teachers who work in primary, middle and high schools in İstanbul and Adana provinces and have professional experience varying between less than one year and forty years. Confirmatory factor analysis included 314 teachers working in schools in İstanbul province with similar experience levels.

First, a draft of 30 items was created based on literature review and expert opinions. The 30 items were then reviewed with opinions from five experts and a five point Likert-type scale of 28 items was created. The confirmatory factor analysis resulted in the final form of the test with 11 items.

Examination of the scale's validity and reliability started with the exploratory factor analysis. The model shaped after the exploratory factor analysis was then subjected to confirmatory 
factor analysis to test for validity. The significance level for both analyses was determined as 0.05. Reliability was tested with the Cronbach Alpha internal consistency coefficient, lower $27 \%$ and upper $27 \%$ t tests in order to find out whether the answer to a given item differentiate between lower and upper groups, and thus to specify the level of discernment (Flanagan, 1952; Otrar ve Argin, 2015; Büyüköztürk, 2018).

\section{Findings and Discussion}

Principal components analysis with exploratory factor analysis resulted with higher than recommended Kaiser Meyer Olkin (KMO) values and Bartlett test was statistically significant, so the data were appropriate for factor analysis. The four-factor structure of the scale explains a high amount of total variance $(\% 67,2)$. Teachers' Opinions Scale about Students' Achievement and Learning (TOS-ASAL) has four factors. The first factor resides in items 8,9 , 10 and 11; the second factor in items 6 and 7; third factor in items 3, 4, and 5 and the fourth factor in items 1 and 2 of the final, 11-item version of the scale. The first, second, third and fourth factor explain $19,1 \%, 16,8 \%, 15,8 \%$ and $15,5 \%$ of the total variance respectively. Total variance explained by these four factors was determined as $67,2 \%$. The first five items of the the four-factor, 11-item final version of the scale are reverse-score items.

Common variance of the 11 items in the final version of the scale appear to be between ,497 and ,908; item factor load values are between ,635 - ,891. Factor variance being ,10 and above; and factor loads being higher than ,32 are considered adequate (Çokluk vd., 2012, s. 223).

The four factors are, respectively, Opinion on the Relationship between Student's Emotional Characteristics and Achievement (items 17, 18, 26 and 27), Opinion on the Relationship between Student's Prelearning and Achievement (items 13 and 14), Opinion on the Relationship between Intelligence and Achievement (items 4, 5 and 6) and Opinion on the Changeability of the Student's Success (items 1 and 2). According to the values, Teachers' Opinions Scale about Students' Achievement and Learning (TOS-ASAL) has 11 items and 4 factors in total.

Confirmatory factor analysis is utilized in validity studies. Confirmatory factor analysis shows that two of the $\chi 2$ /Sd, RMSEA, RMR, GFI, AGFI CFI and IFI fit indices are acceptable and five of them are in good levels. RMSEA (Root Mean Square Error of Approximation) and RMR (Root Mean Square Residual) values point to sufficient fit levels with 0.050 and 0.058 respectively. $\chi 2$ /Sd (1,719), GFI (goodness of fit index; 0.959); AGFI (adjusted goodness of fit index; 0.934), CFI (comparative fit index; 0.950) and IFI (incremental fit index; 0.951) values show good fit levels. It can be said that fit index values from the confirmatory factor analysis make the model acceptable (Çokluk et al., 2012).

The scale's Cronbach Alpha internal consistency coefficient is 0.76. Scale factor values were found as $0.79,0.90,0.69$ and 0.70 from first factor to the fourth factor respectively. These values being higher than 0.70 is deemed sufficient for the reliability of the measurement tool (Büyüköztürk, 2014). Cronbach Alpha values were found generally acceptable, between 0,60 and 0.75 (Özdamar, 2016).

A tool to measure the teacher opinions about student achievements and learning was developed with this study. Exploratory factor analysis has determined that the model designed for the four factor, 11-item Teachers' Opinions Scale about Students' Achievement and Learning (TOS-ASAL) shows good compatibility. The high scores of the scale show that 
the teacher opinions on student achievement and learning are high. The scale can be answered in ten minutes. The first five items are reverse-scored.

\section{Giriş}

Ebeveynlerin gözetiminde başlayan öğrenme süreci, okul öncesi kurumlarına başlayan çocuklar için anaokulları ve anasınıflarında, doğrudan ilkokula başlayan çocuklar için ise ilkokul sinıflarında devam etmektedir. Aile ortamından oldukça farklı olan okul ortamında öğrenmeyi, sosyal aile çevresindeki öğrenmeden farklı boyutlara taşımak okulların öncelikli genel amaçlarındandır. Yoğun bir öğrenme ortamı olması beklenen okullarda "öğrenme" sürecine öğretmenler liderlik etmektedir.

Okullarda öğrenmenin yetenek ve zekâdan bağımsız olarak yürütülebileceği iddiasında olan John Carroll “Okulda Öğrenme Modeli” ile (1963) öğrencilere ihtiyaç duydukları yeterli zaman verildiğinde, herkese eşit zaman verildiği durumdan daha yüksek başarının elde edildiği bir evreye geçilebiliyor. Bu durumdan etkilenerek Bloom tarafından geliştirilen Tam Öğrenme Yöntemi ise değişmez ve doğuştan gelen özellikler yerine, değiştirilebilen yönetilebilen özellikler ile öğrenmeyi ve akademik başarıyı açıklıyor (Yıldıran, 2006). Bloom ve öğrencileri tarafından geliştirilen ve okulda öğrenme ve öğretim alanında yeni bir çığır açan modelin değişkenleri Öğrenci nitelikleri (Bilişsel Giriş Davranışları, Duygusal Giriş Özellikleri), Öğretimin Niteliği ve Öğrenme Ürünleri (Öğrenme Düzeyi ve Çeşidi, Öğrenme Hızı ve Duyuşsal Ürünler) olarak belirlenmiştir (Bloom, 1976). Bloom ve arkadaşları tarafından Carroll'un Okulda Öğrenme Model'inden (1963) etkilenerek geliştirilen Tam Öğrenme Yönteminin iki temel sayıltısından birisi öğrencinin daha önceki öğrenme süreçlerinden oluşan öğrenme özgeçmişinin okuldaki öğrenme süreçlerinde önemli bir etkisinin olduğudur. Diğeri de yöntemin değişkenlerinden olan öğretim hizmetinin niteliğinin bu öğrenci özgeçmişi ile yakından ilişkili olan öğrencinin giriş özelliklerinin her ikisini de değisstirebilecek olmasıdır (Bloom, 1976). Öğretim hizmetin niteliği sadece öğretimin ürünü olarak ortaya çıan öğrencilerin öğrenmelerini etkilemekle kalmayıp, öğrencilerin öğrenme süreçlerini de etkilemektedir (Bloom, 1976). Öğretimin öğrencilerin ihtiyaçlarına göre düzenlenmesi başarı ve öğrenmelerini bu derece de etkiliyorsa, öğretimi düzenleyen öğretmenlerin öğretim hakkındaki görüşleri oldukça önemli olarak değerlendirilmektedir. Öğretmenin sınıf içinde öğretim sırasında kullandığı ipuçları, pekiştireçler ve katılım öğrenci başarısındaki ve öğrenme düzeyinde etkili olan öğretim bileşenleridir. Ayrıca dönüt-düzeltme döngüsü de öğrencilerin başarısı ve öğrenme ürünleri üzerinde çok önemli etkisi olan öğretimin bileşenlerindedir (Bloom, 1971, Yıldıran, 2006). Öğretimin niteliği öğretmenin deneyiminden, eğitiminden ve diğer özelliklerinden ziyade sınıf içinde yaptığı uygulamalar ile yakından ilgilidir. Öğretmenin öğretim hizmetleri çerçevesinde sınıf içinde yaptı̆̆ etkinlikler, sergilediği davranışlar öğretmenin görüş ve inançları ile doğrudan ilgilidir. Çocukların uzun süren okul hayatlarında öğrenmenin temellerini oluşturacak ve hayat boyu öğrenme yetilerini kazandıracak olan öğretmenlerin, öğrenme hakkındaki inançları öğrencilerin öğrenme süreçleri ve ürünleri açısından önem arz etmektedir (Borg, 2001). İnançlar bireyler tarafından doğru kabul edilen, deneyimler ile kazanılan, öznel değer yüklü bilişsel yapılardır (Skott, 2013). Öğretmen inançları da öğretmenlerin sınıf içindeki öğretimi nasıl yorumladıklarını, nasıl uyguladıklarını ve öğrencinin öğrenmesi ve başarısı hakkında nasıl ilerlediklerini gösteren bilişsel yapılar olarak değerlendirilmektedir (Skott, 2015). Öğretmen inançları öğretmenlerin öğrenciler, öğrenme ve öğretim araçları hakkında örtük görüşleri olarak öğrenme ve öğretmeye etki yapmaktadır (Kagan, 1992). 
Öğretmen inançları hakkında 60 yıldan daha uzun süredir araştırmalar yapılmaktadır (Fives ve Buehl, 2012). Türkiye'de ve dünya genelinde yapılan çalışmalarda öğretmenlerin inançlarının kaynakları, öğretmen inançlarının öğrenciyi nasıl etkilediği, öğretmenin sınıf içi uygulamaları ile inançları arasındaki ilişki gibi çok farklı boyutlarda öğretmen inançları hakkında farklı alanlarda çok çeşitli çalışmalar yapılmıştır (Arumugham, 2019; Abu Radwan, 2019; Beck, Czerniack ve Lumpe, 2000; Biesta, Priestley ve Robinson, 2015; Borg, 2011; Borg ve Al-Busaidi, 2012; Danışman ve Karadağ, 2019; Febriyati, 2020; Kahramanoğlu ve Özbakış, 2018; Kotoman, 2008; Kuzborska, 2011; Levitt, 2002; Mansour, 2009; Peyman, Gholam ve Parviz, 2012; Shafee, 2019; Simmons vd., 1999; Yıldırım, Çetinkaya ve Ateş, 2016). Yapılan bu çalışmalarda öğretmenlerin ölçme aracı olarak portfolyo kullanılması hakkındaki görüşlerinden (Arumugham, 2019), yabancı dil öğretiminde aday öğretmenlerin inançlarındaki değişime (Abu Radwan, 2019), öğrenme özerkliği hakkında öğretmen inançları (Borg ve Al-Busaidi, 2012), öğrencilerin yazma özerkliği konusundaki öğretmen inançları (Febriyati, 2020), ilkokul öğretmenlerinin fen öğretimi ve öğrenimi konusundaki inançları (Levitt, 2002), Fen öğretmenlerinin inançları ve uygulamaları arasındaki ilişki (Mansour, 2009) tarafından araştırılan öğretmen inançları ve görüşleri ile farklı çalışmalardır.

Öğretmenlerin mesleklerini gerçekleştirirken öncelikli amaçları, öğrencilerin öğrenmelerini en üst düzeyde sağlamaktır. Öğretmenlerin kullanacakları yöntemlerin seçimlerinde etkili olan faktör, öğretmenlerin insan ve içinde yaşadığ 1 topluma yönelik bakış açılarıdır (Yıldıran, 2006) ve öğretim sonunda elde ortaya çıkan ürünleri açıklamada sahip oldukları bakış açılarını oluşturan inançlarıdır. Bu amaca ulaşabilmek için öğretmenler, farklı yaklaşımlar, değerler dizileri (paradigmalar) belirler ve bunlara uygun çeşitli yöntem ve teknikler ile öğrenmenin gerçekleşmesi için emek harcar (Biçer, Er ve Özel, 2013; Demir ve Akınoğlu, 2010). Öğretmenlerin benimsedikleri yaklaşım, değerler dizisi ve bunlara uygun olarak öğrenme ortamlarında kullandıkları yöntem ve teknikler, öğretmenlerin öğrenme hakkındaki inançları ile ilgilidir (Borko ve Putnam, 1996; Demir ve Akınoğlu, 2010; Demir, 2013; Ediger, 2000; Hashweh0,1996). Buna ilave olarak, öğretmenlerin öğrencilerden beklentileri öğrencilerinin başarı düzeyleri ile doğrudan ilişkilidir (Gales ve Yan, 2001; Sah ve Shah, 2020; Love, 2002; Muijs ve Reynolds, 2002; Rashidi ve Mughadam, 2014; Rosenthall ve Jacobson, 1968, Akt. Yıldıran, 2006). Öğretmenlerin inançlarının ve felsefelerinin değişmesi ile öğretim sürecinde uygulayacakları yöntem ve tekniklerin farklılaşması da söz konusu olabilmektedir (Doğanay, 2011; Golombek, 1998; Pedersen ve Liu, 2003). Sınıf içi uygulamalarında öğretmenler çok farklı yöntem, strateji ve teknikleri kullanmaktadır. Alanyazın incelendiğinde, sınıf içinde öğretmenler tarafından yapılan etkinlikler ve uygulamaların öğretmenlerin inançlarıyla ilişkili olmadığı yönünde çalışmalar (Simmons vd., 1999) olsa da, öğretmen inançları ve öğretmenlerin öğretim sürecinde öğretmen olarak gösterdikleri davranışlar arasında önemli bir ilişki olduğunu ortaya koyan çalışmalar da bulunmaktadır (Abu Radwan, 2019; Beck vd., 2000; Levitt, 2002; Liu, 2003; Turan, 2019). Öğretmenlerin sınıf içinde ve okul ortamında yaptıkları uygulamalar ve inançları arasındaki ilişkinin anlaşılabilmesi için çalışmalar yapılmasını önerilmektedir (Savaşçı-Açıkalın, 2009). Öğretmenlerin inançları kendileri, öğrencileri ve öğretim çerçevesindeki faktörlerden etkilenmektedir (Barab ve Luehmann, 2003; Jones ve Carter, 2007; Remillard, 2005).

Öğretmenlerin sınıf içi öğretimi daha etkin yapmasını mümkün kılmak için öğretim programı öğretmenlerin inançlarında olumlu yönde değişime yol açabilecek şekilde yapılandırılmalıdır (McNeill, Pimentel ve Strauss, 2013). Ayrıca, öğretmenlerin beklentileri öğrencilerinin akademik başarılarını önemli düzeyde etkiliyor ise (Yıldıran, 2006), öğretmenlerin beklenti 
konusundaki tercihlerini etkileyen öğrenme ve öğrenci başarısı hakkındaki görüşleri, öğretimin istendik hedeflerine ulaşması bakımından büyük önem taşımaktadır. Öğretmenlik mesleğinin kendi bakış açılarından anlaşılabilmesi için, öğretmenliği nasıl yaptıklarını belirleyen görüş ve inançlarının da anlaşılması gereklidir (Nespor, 1987). Ayrıca öğretmenlerin öğrenme ortamında bir öğretim aracısı olabilmesi için sahip oldukları inançlar belirleyici rol oynamaktadır (Biesta, Priestley ve Robinson, 2015). Öğretmen inançlarının, görüşlerinin değiştirilebilir olması da (Özmen, 2012; Tam, 2015) öğretmen inançlarının, görüşlerinin belirlenmesini gerekli kılmaktadır. Kagan (1992) öğretmen inançlarını öğretmenlerin öğrenciler, öğrenme ve öğretim araçları hakkında örtük görüşleri olarak tanımlamaktadır. Bu çalışmada bu tanım temel alınmıştır.

Öğretmenin öğrencinin başarısı ve öğrenme konusundaki görüşlerinin belirlenmesi, öğrencilerin öğrenme düzeylerinin yükseltilmesi bakımından önemli olarak değerlendirilmektedir. Öğrencilerin öğrenmesi ve başarısını etkilemesi bakımından önemli olarak değerlendirilen öğretmen görüşlerinin ölçülebilmesini hedefleyen bir ölçme aracı geliştirmek bu çalışmanın konusu olmuştur.

Çalışmanın amacı, öğrencilerin başarısı ve öğrenmesine yönelik öğretmen görüşlerini belirleyebilen, geçerlilik ve güvenirlik düzeyi yüksek olan bir ölçme aracı geliştirmektir.

\section{Yöntem}

Araştırmanın modeli, mevcut durumu tespit etmeyi amaçladığı için tarama modelidir. Tarama araştırmaları bir konuya ya da olaya ilişkin katılımcıların görüşlerinin ya da ilgi, beceri, yetenek, tutum vb. özelliklerinin belirlendiği genellikle diğer araştırmalara göre görece daha büyük örneklemler üzerinde yapılan araştırmalardır (Balcı, 2008).

\section{Evren ve Örneklem}

Örnekleme kararlarını etkileyen etkenlerden en önemlileri örneklem büyüklüğü, temsiliyet ve kullanılan örnekleme stratejisidir (Cohen, Manion ve Morrison, 2007).Bu kararların verilmesinde örneklem stratejisi ve çalışmanın paradigması etkilidir. Örnekleme, bir araştırmanın konusunu oluşturan evrenin bütün özelliklerini yansıtan bir parçasının seçilmesi işlemini belirtir. Bu çalışma nicel paradigmaya dayalı bir tarama araştırması olması dolayısıyla örneklemeden evrene genellenebilirlik önem taşımaktadır. Bu durum temsiliyet etkenini öne çıkarmaktadır (Cohen vd., 2000).

Bu çalışmanın evrenini ilkokul, ortaokul ve lise düzeylerinde çalışmakta olan ve öğretmenlik meslekleri içindeki son 2 yıl içinde İstanbul ve Adana illerinde hizmet içi eğitimlere katılan mesleki deneyim süresi bir yıldan az ile kırk yıl arasında değişen öğretmenler oluşturmaktadır. Bu özellikleri taşıdığı tespit edilen öğretmenlere gönderilen çevrimiçi anket formları eposta adreslerine gönderilmiştir. Anket formlarını doldurma talebimize olumlu cevap veren katılımcı öğretmenlerin cevapları dikkate alınmıştır. Bu anakütleden katılımcı seçimi sürecinde ön deneme aşaması hariç temsiliyet ölçütü birinci planda göz önünde bulundurulmuştur. Talebe olumlu cevap verme durumunun temsiliyet etkenini zedelemeyeceği varsayılmıştır. Katılımcı öğretmenlerin sayıları, ön deneme aşamasında 37, açıklayıcı faktör analizinde (AFA) 285 ve doğrulayıcı faktör analizinde (DFA) 314 olmak üzere toplam 636'dir.

Ön-deneme çalışması için bir okulda görev yapmakta olan öğretmenlerden gönüllü olan 37 öğretmen katılımı sağlanmıştır. Bu aşamada bir örnekleme stratejisi kullanılmamış, yalnızca 
formdaki ifadelerin anlaşılabilirliği test edilmiştir. AFA çalışmasında ise veri toplama işlemi İstanbul ve Adana illerindeki okullarda görev yapan öğretmenlerin cevaplarına dayalı olarak yapılmıştır. Cevaplanan ölçeklerde gerekli incelemeler yapıldıktan sonra 285 cevap formunun tamamı değerlendirmeye alınmıştır.

DFA çalışmasında İstanbul ilinde çeşitli okullarda çalışan öğretmenlere gönderilmiş olan elektronik ölçek formunu 314 gönüllü öğretmen cevaplayarak geri dönüş yapmıştır.

\section{Ölçeğin Geliştirilmesi}

Ölçek Geliştirme Düşüncesinin Oluşması (Problemin Gerçek Hayatta Ortaya Çıkışı): Araştırmacının kurumsal gelişim konusunda çalıştı̆̆ bir okulda, okul yönetiminde oluşan "öğretmenlerin farklı öğretim yaklaşımları sergilemesinin, öğretmenin hangi özelliklerinden kaynaklandığı konusundaki” soruya cevap aramasıyla başlamıştır. Öğrencilerin başarısı ve öğrenmesine yönelik öğretmen görüşlerini belirlemek amacıyla alanyazın taraması ve uzman görüşü alınması sonucu 30 maddeden oluşan bir taslak hazırlanmıştır. Maddeler, kapsam geçerliliği için beş uzmandan (iki Eğitim Programları ve Öğretim; bir Ölçme-Değerlendirme; bir Eğitim Yönetimi; bir Türkçe dil uzmanı) görüş alınarak 30 madde incelenmiştir. Uzmanlardan her madde için "Uygun ve Uygun Değil" aralığında "Çok Uygun (4), Uygun (3), Geliştirilmeli (2) Ve Uygun Değil (1)" şeklinde puanlamaları istenmiştir. En az üç uzmanın uygun ve çok uygun olarak nitelendirdiği maddeler kabul edilmiştir. Bu süreç sonucunda iki madde ölçekten çıkarılmış; üç madde ise düzenlenerek ölçeğe alınmış ve sonuçta 28 maddelik Likert tipi bir ölçek oluşturulmuştur. Likert tipi ölçekte kullanılan beş düzeyli derecelendirme; (5) Kesinlikle Katılıyorum; (4) Katılıyorum; (3) Kısmen katılıyorum; (2) Katılmıyorum ve (1) Kesinlikle Katılmıyorum olarak düzenlenmiştir. Maddelerin 12 tanesi ters puanlanan madde olarak yer almıştır. Maddeler teste rastgele olarak tesadüfi bir şekilde sıralanmıştır. Öndeneme çalışması 37 öğretmen ile gerçekleştirilmiş, daha sonra AFA için 285; DFA için de 314 öğretmen adayı ile çalışma gerçekleştirilmiştir. Ön deneme sonunda 28 maddelik test ile $\mathrm{AFA}^{\prime}$ da da devam edilmiş, DFA'da ise 11 maddelik testin son durumu elde edilmiştir.

\section{Verilerin Çözümlenmesi}

Gerçekleştirilen AFA çalışmaları ile ölçeğin geçerlik ve güvenirlik çalışmalarına başlanmıştır. AFA'dan sonra ortaya çıkan model Amos programı ile DFA gerçekleştirilerek geçerlik çalışması yapılmıştır. Her iki analiz için anlamlılık düzeyi 0,05 olarak belirlenmiştir. Maddeye verilen cevabın alt ve üst gruplar arasında farklılaşıp farklılaşmadığı ve dolayısıyla ayırt etme gücünü ortaya koyma amacıyla Cronbach Alfa iç tutarlılık katsayısı, alt \%27'lik ve üst \%27'lik t testi değerleri ile güvenirlik çalışması yapılmıştır (Flanagan, 1952; Otrar ve Argın, 2015; Büyüköztürk, 2018).

Tablo 1. Öğrencilerin Demografik Yapısına İlişkin Frekans ve Yüzde Değerleri

\begin{tabular}{llcc}
\hline Değişkenler & Gruplar & $f$ & $\%$ \\
\hline \multirow{2}{*}{ Cinsiyet } & Kiz & 316 & 49,8 \\
& Erkek & 319 & 50,2 \\
\hline \multirow{2}{*}{ Ailenin bilgisayar oyunu oynarken süre sinırı koyması } & Hayır & 198 & 31,2 \\
& Evet & 437 & 68,8 \\
\multirow{2}{*}{ Aileni benzer şekilde bilgisayar oyunu oynaması } & Hayır & 326 & 51,3 \\
& Evet & 309 & 48,7 \\
\hline Toplam & & 405 & 100 \\
\hline
\end{tabular}


Örneklem grubunun \%50,2 (319)'si erkek öğrenciler, \%49,8 (316)'i k1z öğrenciler oluşturmaktadir.

\section{Bulgular}

Öğrencilerin başarısı ve öğrenmesine yönelik öğretmen görüşleri ölçeğinin geliştirilmesi için bu çalışma gerçekleştirilmiştir. Geliştirilmesi hedeflenen ölçeğin geçerlik düzeyini belirlemek amacıyla AFA ve DFA kullanılmış ve güvenirlik analizi yapılmıştır.

\section{Açıklayıcı Faktör Analizi Çalışmaları}

Öğrencilerin Başarısı ve Öğrenmesine Yönelik Öğretmen Görüşleri Ölçeğine (ÖBÖY-ÖGÖ) çok değişkenli bir veri kümesi içindeki bilgi kaybını azaltmak maksadıyla daha az değişkenle açıklamakta kullanılan istatistiksel bir model olan temel bileşenler analizi (Jolliffe, 2002) uygulanmıştır. Analize tabi tutulan 28 maddelik ölçeğin bu analizden önce faktör analizine uygunluğunun değerlendirilebilmesi için 0,30 ve daha yüksek düzeyde pek çok katsayının varlığınınım ortaya konulması gerekmektedir (Bayram, 2004). Korelasyon matrisinin incelenmesi sonucunda 00,30 ve daha yüksek düzeyde pek çok katsayının varlı̆̆ı ortaya konulmuştur. Ayrıca anti-image matrisinde ana eksen elemanları incelendiğinde bu eksendeki 28 maddeye ait değerlerin 00,50 değerinin üzerinde olduğu belirlenmiştir. Maddelerin ölçekte yer alma yeterliliği, Kaiser- Mayers- Olkin "measures of sample adequacy" (KMO-MSA) değeri, 00,50 üzerinde olması o maddenin ölçekte yer alabileceğinin bir göstergesidir (Özdamar, 2016).

Tablo 1: Öğrencilerin Başarısı ve Öğrenmesine Yönelik Öğretmen Görüşleri Ölçeği (ÖBÖY-ÖGÖ) KMO ve Bartlett's Test Değerleri

\section{KMO and Bartlett's Test}

\begin{tabular}{lll}
\hline \multicolumn{2}{l}{ Kaiser-Meyer-Olkin Measure of Sampling Adequacy } & 0,719 \\
\hline Bartlett's Test of Sphericity & $\chi^{2}$ & 2032,565 \\
\cline { 2 - 2 } & $\mathrm{Sd}$ & 378 \\
\hline
\end{tabular}

Tablo 1'de görüleceği üzere Kaiser- Meyers-Olkin değeri 0,719 ( $p<.01)$ ve Bartlett's değeri 2032,565 olarak ortaya çıkmıştır. Bu değer tavsiye edilen 00,60 değerinin üzerindedir (Kaiser, 197,1974 akt. Pallant, 2016). Bartlett testi de istatiksel anlamlılığa ulaşmıştır (Bartlett, 1954, akt. Pallant, 2016).

Yapılan Temel Bileşenler Analizi ile öz değeri 1'in üstünde olan 10 tane bileşenin varlığ görülmüştür. Bu bileşenler varyansın, sırasıyla, \%13,516, \%11,691, \%7,955, \%6,214, \%4,908, $\% 4,525, \% 4,351, \% 30,996, \% 30,704$ ve \%30,600’sını açılamaktadır.

Ortaya çıkan yamaç ve birikinti grafiği ise dördüncü faktörden (Şekil 1) itibaren kırılmanın açık bir biçimde olduğunu göstermektedir. Cattell yamaç testi kullanılarak (Cattell, 1966) daha sonra yapılacak analizler için dört bileşenin elde tutulmasına karar verilmiştir. 


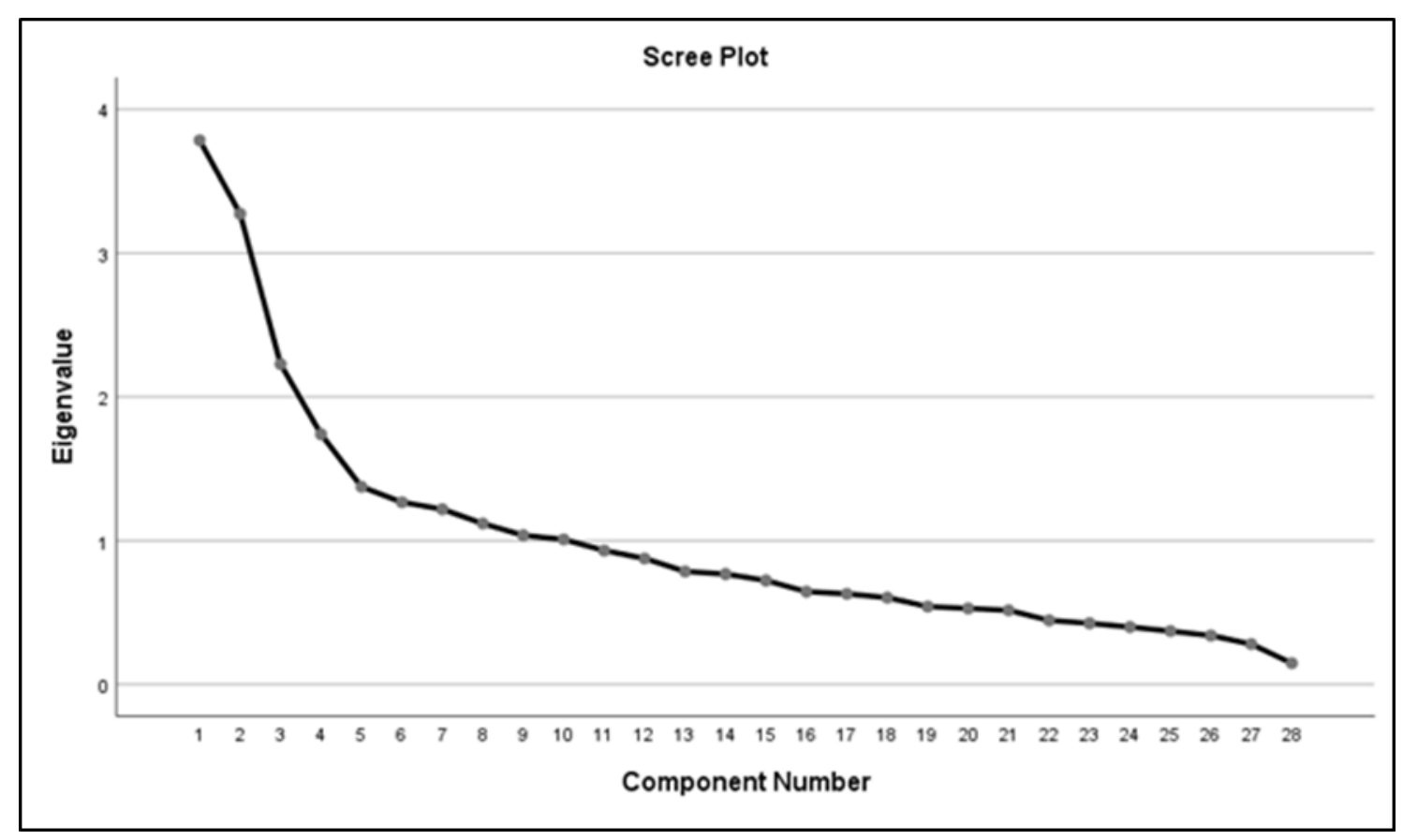

Şekil 1. Yamaç-Birikinti Grafiği

Bu kararı paralel analiz sonuçları da desteklemektedir. Aynı büyüklükte oluşturulmuş bulunan (28 değişken x 285 katılımcı) veri matrisine karşılık gelen değerleri aşabilen sadece dört bileşenin olduğu belirlenmiştir (Pallant, 2016).

Tablo 2. ÖBÖY-ÖGÖ Faktör Analizi Sonuçları

\begin{tabular}{ccccc}
\hline Madde No & $\mathbf{X}$ & ss & Faktör Ortak Varyans & Faktör Yük Değeri \\
\hline 17 & 3,7611 & 1,0001 & 0,467 & 0,654 \\
\hline 18 & 3,2389 & 0,8541 & 0,487 & 0,635 \\
\hline 26 & 3,6465 & 1,0780 & 0,654 & 0,791 \\
\hline 27 & 3,4809 & 1,1422 & 0,669 & 0,788 \\
\hline 13 & 3,0955 & 1,0681 & 0,900 & 0,941 \\
\hline 14 & 3,0796 & 1,0798 & 0,908 & 0,939 \\
\hline 4 & 2,0796 & 0,9741 & 0,525 & 0,821 \\
\hline 5 & 2,0669 & 0,9751 & 0,486 & 0,715 \\
\hline 6 & 2,1592 & 1,0423 & 0,683 & 0,677 \\
\hline 1 & 2,0987 & 1,0298 & 0,797 & 0,891 \\
\hline 2 & 1,6401 & 0,8541 & 0,812 & 0,889
\end{tabular}

Tablo 2 incelendiğinde faktör varyans değerlerinin 0,467 ile 0,900 arasında değerlere sahip olduğu görülmektedir. Ölçekte yer alan maddelerin faktör yük değerleri ise 0,635 ile 0,941 arasındadır. Bu değerler kabul edilebilir olan 0,40 değerinden daha yüksektir (İslamoğlu ve Alnıaçık, 2016: 437).

Tablo 3: ÖBÖY-ÖGÖ'nin Alt Boyutları Tarafından Açıklanan Varyans Oranları

\begin{tabular}{ccccccc}
\hline \multirow{2}{*}{ Faktör } & \multicolumn{3}{c}{ Başlangıç Özdeğerleri } & \multicolumn{2}{c}{ Döndürme Sonrası Toplam Yükler } \\
\cline { 2 - 7 } & Toplam & Varyans \% & Kümülatif \% & Toplam & Varyans \% & Kümülatif \\
\hline 1 & 2,748 & 24,984 & 24,984 & 2,105 & 19,132 & 19,132 \\
\cline { 2 - 7 }
\end{tabular}




\begin{tabular}{lllllll}
\cline { 2 - 6 } 2 & 1,730 & 15,731 & 40,714 & 1,849 & 16,805 & 35,937 \\
\hline 3 & 1,576 & 14,330 & 55,044 & 1,734 & 15,767 & 51,703 \\
\hline 4 & 1,332 & 12,111 & 67,155 & 1,700 & 15,452 & 67,155 \\
\hline
\end{tabular}

Tablo 3'deki bulgular incelendiğinde ortaya çıkan dört bileşenli yapı varyansın \%67,2'sini açılamakta olduğu ortaya çıkmaktadır. Bu dört bileşenin katkısı, birinci bileşen için \%19,1; ikinci bileşen için \%16,8; üçüncü bileşen için \%15,8 ve dördüncü bileşen için $\% 15,5$ olarak bulunmuştur. Dört bileşenin yorumlanabilmesi için varimax döndürme gerçekleştirilmiştir. Ayrıca oblimin döndürme ile de benzer sonuçlar elde edilmektedir. Dört faktörlü olan ÖBÖYÖGÖ’nin \%67,155 olan toplam varyansının yeterli olduğu söylenebilir (Büyüköztürk, 2018).

Tablo 4: ÖBÖY-ÖGÖ'nin Alt Boyutlarının Maddelerine İlişkin Faktör Yükleri

\begin{tabular}{|c|c|c|c|c|c|c|}
\hline \multirow[b]{2}{*}{ Boyut Adı } & \multirow{2}{*}{$\begin{array}{l}\text { İlk (Son)* } \\
\text { Ölçek } \\
\text { Madde No }\end{array}$} & \multirow{2}{*}{$\begin{array}{c}\text { Ortak } \\
\text { Faktör } \\
\text { Varyansı }\end{array}$} & \multicolumn{4}{|c|}{ Faktör Yükleri } \\
\hline & & & $\begin{array}{c}1 . \\
\text { Boyut }\end{array}$ & $\begin{array}{c}2 . \\
\text { Boyut }\end{array}$ & $\begin{array}{c}3 . \\
\text { Boyut }\end{array}$ & $\begin{array}{c}4 . \\
\text { Boyut }\end{array}$ \\
\hline \multirow{4}{*}{$\begin{array}{l}\text { FAKTÖR } 1 \text { Öğrencinin Duyuşsal } \\
\text { Özellikleri ile Başarı İlişkisine Yönelik } \\
\text { Görüş }\end{array}$} & $17(8)^{*}$ & 0,467 & 0,654 & & & \\
\hline & $18(9)^{*}$ & 0,487 & 0,635 & & & \\
\hline & $26\left(10^{*}\right)$ & 0,654 & 0,791 & & & \\
\hline & $27(11)^{*}$ & 0,669 & 0,788 & & & \\
\hline \multirow{2}{*}{$\begin{array}{l}\text { FAKTÖR } 2 \text { Öğrencinin Ön } \\
\text { öğrenmeleri ile Başarı İlişkisine } \\
\text { Yönelik Görüş }\end{array}$} & $13(6)^{*}$ & 0,900 & & 0,941 & & \\
\hline & $14(7)^{*}$ & 0,908 & & 0,939 & & \\
\hline \multirow{3}{*}{$\begin{array}{l}\text { FAKTÖR } 3 \text { Zekâ ile Başarı İlişkisine } \\
\text { Yönelik Görüş }\end{array}$} & $4(3)^{*}$ & 0,525 & & & 0,821 & \\
\hline & $5(4)^{*}$ & 0,486 & & & 0,715 & \\
\hline & $6(5)^{*}$ & 0,683 & & & 0,677 & \\
\hline \multirow{2}{*}{$\begin{array}{l}\text { FAKTÖR } 4 \text { Öğrencinin Başarısının } \\
\text { Değiştirilebilirliğine Yönelik Görüş }\end{array}$} & $1(1)^{*}$ & 0,797 & & & & 0,891 \\
\hline & $2(2)^{*}$ & 0,812 & & & & 0,889 \\
\hline
\end{tabular}

Tablo 4' göre bu dört bileşen sırasıyla, Öğrencinin Duygusal Özellikleri ile Başarı İlişkisine Yönelik Görüşler (17., 18., 26. ve 27. Maddeler), Öğrencinin Ön öğrenmeleri ile Başarı İlişkisine Yönelik Görüşler (13. ve 14. Maddeler), Zekâ ile Başarı İlişkisine Yönelik Görüşler (4., 5. ve 6. Maddeler) ve Öğrencinin Başarısının Değiştirilebilirliğine Yönelik Görüşler (1. ve 2. Maddeler) olarak ortaya çıkmıştır (Tablo 4). Ortaya çıkan değerlere göre, Öğrencilerin Başarısı ve Öğrenmesine Yönelik Öğretmen Görüşleri Ölçeği (ÖBÖY-ÖGÖ) toplam 11 madde ve dört boyuttan oluşmaktadır.

Ölçeğin son halinde bulunan 11 maddenin ortak faktör varyans değerlerinin 0,467 ile 0,908 arasında olduğu görülmektedir (Tablo 4). Ölçek maddelerine ait faktör yükleri de 0,635 - 0,891 arasında değerler almaktadır. Faktör varyansının; 0,10 ve üzerinde; faktör yüklerinin de 0,32 den yüksek olması yeterli olarak değerlendirilmektedir (Çokluk vd., 2012, s. 223).

Tablo 5: ÖBÖY-ÖGÖ’nin Boyutları ve Testin Cronbach Alfa Değerleri 


\begin{tabular}{ll}
\hline $\begin{array}{l}\text { FAKTÖR 1 Öğrencinin Duygusal Özellikleri ile Başarı İlişkisine Yönelik } \\
\text { Görüş }\end{array}$ & 0,792 \\
\hline $\begin{array}{l}\text { FAKTÖR 2 Öğrencinin Ön öğrenmeleri ile Başarı İlişkisine Yönelik } \\
\text { Görüş }\end{array}$ & 0,902 \\
\hline FAKTÖR 3 Zekâ ile Başarı İlişkisine Yönelik Görüş & 0,689 \\
\hline FAKTÖR 4 Öğrencinin Başarısının Değiştirilebilirliğine Yönelik Görüş & 0,701 \\
\hline ÖBÖY-ÖGÖ & 0,756 \\
\hline
\end{tabular}

ÖBÖY-ÖGÖ ve boyutlarının iç tutarlılık düzeyleri Tablo 5'de verilmiştir. Cronbach Alfa katsayısı ölçeğin genel güvenirliğini değerlendirmek amacıyla kullanılır. Cronbach Alfa $(\alpha)$ katsayısının değeri $0,60 \leq \alpha<0,70$ arasında ise yeterli; $70 \leq \alpha<0,80$ arasında ise yüksek güvenirlik düzeyine sahiptir (Özdamar, 2016). Sonuçlar ÖBÖY-ÖGÖ’nin güvenilir bir ölçme aracı olduğunu göstermektedir.

Tablo 6. ÖBÖY-ÖGÖ'nin Boyutları ile İlişkisine Gösteren Pearson Korelasyon Katsayıları

\begin{tabular}{lcc}
\hline \multicolumn{1}{c}{ Boyutlar } & r & p \\
\hline $\begin{array}{l}\text { ÖBÖY-ÖGÖ ve FAKTÖR 1 Öğrencinin Duygusal Özellikleri ile Başarı İlişkisine } \\
\text { Yönelik Görüş }\end{array}$ & 0,691 & 0,000 \\
\hline $\begin{array}{l}\text { ÖBÖY-ÖGÖ ve FAKTÖR 2 Öğrencinin Ön öğrenmeleri ile Başarı İlişkisine } \\
\text { Yönelik Görüş }\end{array}$ & 0,614 & 0,000 \\
\hline $\begin{array}{l}\text { ÖBÖY-ÖGÖ ve FAKTÖR 3 Zekâ ile Başarı İlişkisine Yönelik Görüş } \\
\text { ÖBÖY-ÖGÖ ve FAKTÖR 4 Öğrencinin Başarısının Değiştirilebilirliğine Yönelik } \\
\text { Görüş }\end{array}$ & 0,693 & 0,000 \\
\hline
\end{tabular}

Tablo 6' da ÖBÖY-ÖGÖ ölçeğinin kendisiyle her bir alt boyutu arasındaki korelasyon değerleri değerin gücü ve istatistiksel anlamlılığı açısından incelenmiştir. İnceleme sonucunda ana ölçeğin her bir alt boyutla olan korelasyon değerlerinin tamamı istatistiksel anlamı ölçülerde orta-yüksek arası ilişki gösterir şekilde(0,543 -0,693 arasında) bulunmuştur.

\section{Doğrulayıcı Faktör Analizi Çalışmaları}

AFA ile belirlenen beş faktör 11 maddeden oluşan ölçek çeşitli okullarda çalışan öğretmenlere gönderilmiş 314 gönüllü öğretmen ölçeği cevaplayarak geri dönüş yapmıştır. Cronbach Alpha ( $\alpha$ ) katsayısı 00,756 olarak bulunmuştur. Çeşitli branşlardan 314 öğretmenin ölçeğe verdiği cevaplar ile yapılan DFA sonuçlarına göre birinci sıra DFA'daki ki-kare uyum testi, RMR, GFI, AGFI, CFI ve RMSEA uyum indeksleri incelenmiştir.

Uyum indekslerinden elde edilen değerler "kabul edilebilir uyum" ve "iyi uyum" arasında değişir şekilde bulunmuştur. Tüm faktörler istatistiksel olarak anlamlı bulunmuş ve uyum indeksleri sonucunda elde edilen modelin iyi bir uyuma sahip olduğu ortaya koyulmuştur (Tablo 7) (Gürbüz ve Şahin, 2018).

Tablo 7. On Bir Maddeli Ölçeğin Doğrulayıcı Faktör Analizine İlişkin Uyum İndeks Değerleri*

\begin{tabular}{ccccc}
$\begin{array}{c}\text { İyilik Uyum } \\
\text { İndeksi }\end{array}$ & $\begin{array}{c}\text { Ulaşılan } \\
\text { Değerler }\end{array}$ & $\begin{array}{l}\text { İyi Uyum } \\
\text { Değerler* }^{*}\end{array}$ & $\begin{array}{c}\text { Kabul Edilir } \\
\text { Değerler* }^{*}\end{array}$ & Uyum Durumu \\
\hline
\end{tabular}




\begin{tabular}{cccll}
\hline$\chi^{2} /$ Sd & 1,719 & $\leq 3$ & $\leq 5$ & İyi Uyum \\
\hline Sd & 41 & & & \\
\hline RMSEA & 0,50 & $\leq 0.05$ & $\leq 0.08$ & Kabul Edilebilir Uyum \\
\hline RMR & 0,58 & $\leq 0.05$ & $\leq 0.10$ & Kabul Edilebilir Uyum \\
\hline GFI & 0,959 & $\geq 0.95$ & $\geq 0.90$ & İyi Uyum \\
\hline AGFI & 0,934 & $\geq 0.95$ & $\geq 0.90$ & İyi Uyum \\
\hline CFI & 0,950 & $\geq 0.95$ & $\geq 0.90$ & İyi Uyum \\
\hline IFI & 0,951 & $\geq 0.95$ & $\geq 0.90$ & İyi Uyum \\
\hline
\end{tabular}

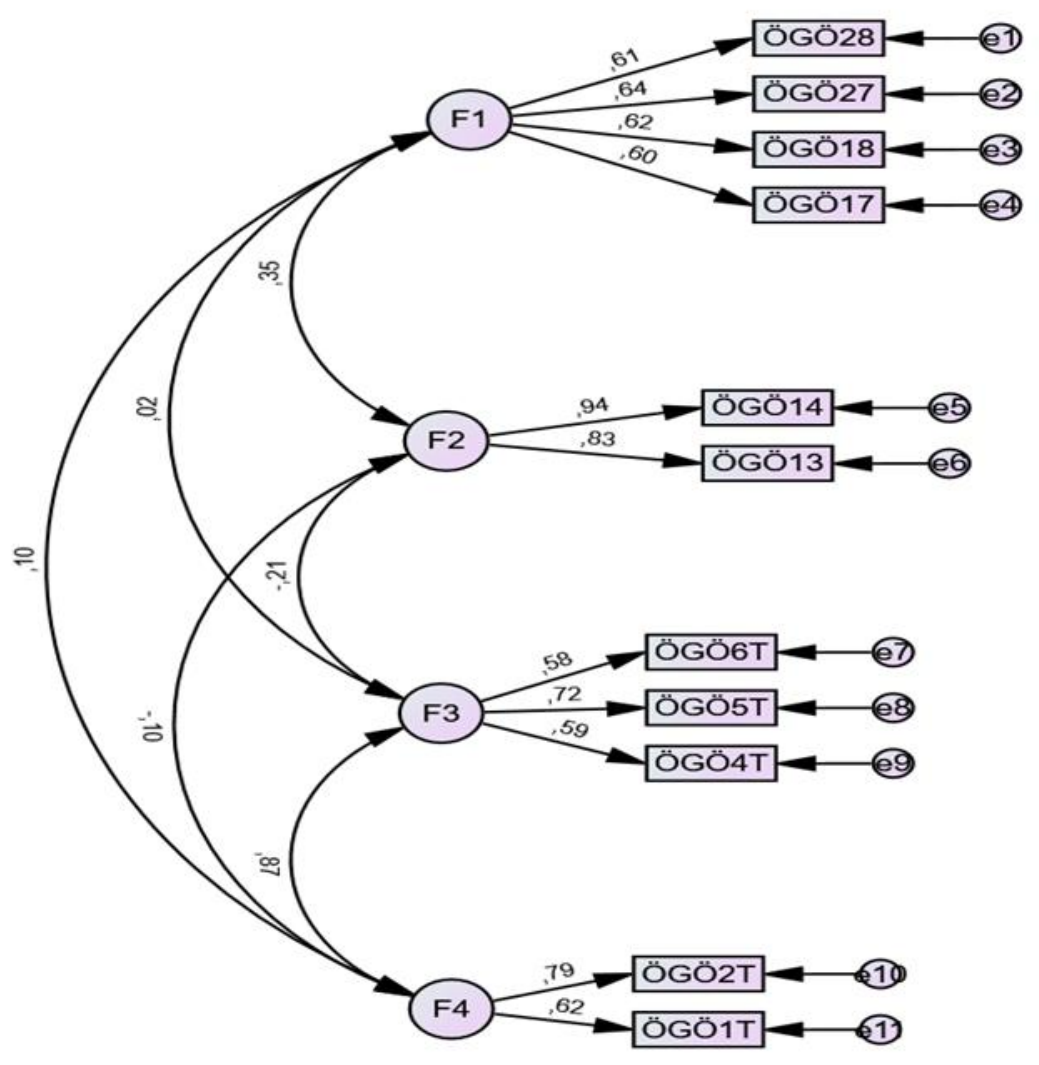

Şekil 2. Yol-Diyagramı

Şekil 2'deki yol diyagramı incelendiğinde maddelerin sahip olduğu faktör yüklerinin 0,61 ile 0,94 değerleri arasında değiştiği görülmektedir. Maddelerin faktör yüklerine ait değerlerin .32 den yüksek olması kabul edilen sınırın üstündedir (Çokluk vd., 2012). 


\section{Tartışma}

$\mathrm{Bu}$ araştırma sürecinde öğrencilerin başarısı ve öğrenmesine yönelik öğretmen görüşlerini belirleyebilen bir ölçek geliştirme çalışması yapılmıştır. Literatür taraması ve uzman görüşlerinden yararlanılarak hazırlanan 5'li Likert tipi 30 maddeden oluşan ölçek kapsam geçerliği çalışması ile 28 maddelik yapısına kavuşmuş ve deneme çalışması sonrası faktör analizi aşamasına geçilmiştir.

AFA yapılan temel bileşenler analizi sonucunda Kaiser Meyer Olkin (KMO) değerinin tavsiye edilen değerinin üzerinde olması ve Bartlett testinin de istatiksel anlamlılığa ulaştığının anlaşılması neticesinde, verilerin faktör analizine uygun bulunmuştur. Ölçeğin dört faktörlü yapısı toplam varyansın yüksek bir miktarını $(\% 67,155)$ açıklamaktadır. Öğrencilerin Başarısı ve Öğrenmesine Yönelik Öğretmen Görüşleri Ölçeği (ÖBÖY-ÖGÖ) dört boyuta sahiptir. Birinci boyut ölçeğin 11 maddelik son halinde 8., 9.,10. ve 11. maddeler olarak yer almaktadır. Ölçeğin ikinci boyutu ölçeğin son halinde 6 . ve 7. maddeler olarak yer almaktadır. Ölçeğin üçüncü boyutu son formunda 3. ,4. ve 5. maddeler; dördüncü boyutum maddeleri ise 1 . ve 2 . maddeler olarak son halinde de aynı madde numaraları ile yer almaktadır. Birinci boyut toplam varyansın $\% 19,1$ 'ini; ikinci boyut $\% 16,8$ 'ini; üçüncü boyut $\% 15,8$ 'ini ve dördüncü boyut ise $\% 15,5$ 'ini açıklamaktadır. Bu dört boyut tarafından açıklanan toplam varyans ise $\% 67,2$ olarak belirlenmiştir. Ölçeğin oluşan dört boyutlu 11 maddeli son halinde ilk beş madde ters puanlanan maddelerdir.

Bu dört bileşen sırasıyla, Öğrencinin Duygusal Özellikleri ile Başarı İlişkisine Yönelik Görüş (17., 18., 26. ve 27. Maddeler), Öğrencinin Ön öğrenmeleri ile Başarı İlişkisine Yönelik Görüş (13. ve 14. Maddeler), Zekâ ile Başarı İlişkisine Yönelik Görüş (4., 5. ve 6. Maddeler) ve Öğrencinin Başarısının Değiştirilebilirliğine Yönelik Görüş (1. ve 2. Maddeler) olarak ortaya çıkmıştır. Ortaya çıkan değerlere göre, Öğrencilerin Başarısı ve Öğrenmesine Yönelik Öğretmen Görüşleri Ölçeği (ÖBÖY-ÖGÖ) toplam 11 madde ve dört boyuttan oluşmaktadır.

DFA geçerlilik çalışmalarında yapılan diğer bir analizdir. DFA'da ortaya çıkan uyum indeksleri incelendiğinde, $\chi 2$ /Sd, RMSEA, RMR, GFI, AGFI CFI ve IFI uyum indekslerinden ikisinin kabul edilebilir uyum düzeyinde, beşinin ise iyi uyum düzeyinde olduğu belirlenmiştir. RMSEA (yaklaşık hataların ortalama karekökü) 0,50 ve RMR (artık ortalamaların karekökü) 0,58 değerleri ile kabul edilebilir uyum düzeyine işaret etmektedir. ұ2 /Sd değeri 1,719; GFI (iyilik uyum indeksi) 0,959; AGFI (düzeltilmiş iyilik uyum indeksi) 0,934; CFI (karşılaştırmalı uyum indeksi) 0,950 ve IFI (fazlalık uyum indeksi) 0,951 değerleri ise iyi uyum düzeyinde olduğunu göstermektedir. DFA sonucunda elde edilen uyum indeksleri incelendiğinde ortaya çıkan değerlerin modelin kabul edilebilmesini mümkün kıldığı söylenebilir (Çokluk vd., 2012).

Ölçeğin Cronbach Alfa iç tutarlılık katsayısı ise 0,76'dir. Ölçek boyutlarının ise birinci boyuttan dördüncü boyuta doğru sırasıyla $0,79,0,90,0,69$ ve 0,70 olarak bulunmuştur. Bu değerin 0,70 ' den yüksek olması ölçme aracının güvenirliği için yeterli kabul edilmektedir (Büyüköztürk, 2014). Cronbach Alfa değerinin 0,60 ve 0,75 arasındaki değerler için genel kabul gören düzeylerde olduğu değerlendirilmektedir (Özdamar, 2016).

AFA ile dört faktörlü 11 maddeden oluşan Öğrencilerin Başarısı ve Öğrenmesine Yönelik Öğretmen Görüşleri Ölçeği (ÖBÖY-ÖGÖ) için tasarlanan modelin iyi bir uyum gösterdiği belirlenmiştir. Ölçekten alınan puanların yüksekliği öğretmenlerin öğrencilerin başarısı ve 
öğrenmesine yönelik görüşlerinin yüksek olduğunu göstermektedir. Ölçek azami on dakikalık sürede cevaplanabilmektedir. Ölçekte ilk beş madde ters puanlanmaktadır.

Yapılan çalışma ile öğrencilerin başarısı ve öğrenmesine yönelik olarak öğretmenlerin görüşlerini ölçen bir ölçme aracı geliştirilme süreci tamamlanmıştır.

\section{KAYNAKÇA}

Abu Radwan, A. (2019). Changes in prospective teachers' beliefs about foreign language learning in a teacher training program. Sultan Qaboos University Journal of Arts \& Social Sciences, 10(2), 37-48.

Arumugham, K.S. (2019). Teachers' understanding towards portfolio assessment: A case study among Malaysian primary school teachers. Problems of Education in the 21st Century, 77(6), 695-704.

Balc1, A. (2008). Sosyal Bilimlerde Araştırma (6. baskı). Ankara: Pegem Yayıncılık.

Barab, S.A. \& Luehmann, A.L. (2003). Building sustainable science curriculum: Acknowledging and accommodating local adaptation. Science Education, 87, 454-467.

Bayram, N. (2004). Sosyal Bilimlerde SPSS İle Veri Analizi. Bursa: Ezgi Kitabevi. Büyüköztürk, Ş. (2004). Sosyal Bilimler İçin Veri Analizi El Kitabı (4. Basım).

Beck, J., Czerniak, C.M. \& Lumpe, A.T. (2000). An Explanatory study of teachers' beliefs regarding the implementation of constructivism in their classrooms. Journal of Science Teacher Education, 11(4), 323-340.

Biçer, B., Er, H. ve Özel, A. (2013). Öğretmen adaylarının epistemolojik inançları ve benimsedikleri eğitim felsefeleri arasındaki ilişki. Ĕ̆itimde Kuram ve Uygulama 9(3) 229242.

Biesta, G., Priestley, M. \& Robinson, S. (2015). The role of beliefs in teacher agency, Teachers and Teaching, 21(6), 624-640, doi: 10.1080/13540602.2015.1044325

Bloom, B.S. (1971). Individual differences in school achievement: A vanishing point, A Monograph. AERA-pdk Award Lecture Annual Meeting American Educational. Research Association New York.

Bloom, B.S. (1976). Human characteristics and school learning. New York: McGraw Hill.

Borg, M. (2001). Teachers' beliefs. ELT Journal 55 (2), 186-188. https.

Borg, S. \& Al-Busaidi, S. (2012). Learner autonomy: English language teachers' beliefs and practices. Www.britishcouncil.org. Received in 05.06 .2020 from: https://www. teachingenglish.org.uk/sites/teacheng/files/b459\%20ELTRP\%20Report\%20Busaidi_fin $\underline{\text { al.pdf }}$

Borko, H. (2004). Professional development and teacher learning: mapping the terrain. Educational Researcher, 33(8).

Borko, H. \& Putnam, R. (1996). Learning to teach. In D. Berliner, \& R. Calfee (Eds.), Handbook of Educational Psychology (673-708). New York: MacMillan.

Büyüköztürk, Ş. (2018). Sosyal bilimler için veri analizi el kitabı. Ankara: Pegem A Akademi.

Carroll, J. B. (1963). A model of school learning. Teachers College Record, 64(8), 723-733. 
Cattell, R. B. (1966). The Scree Plot Test for the Number of Factors. Multivariate Behavioral Research, 1, 140-161.

Cohen, L.; Manion; L. \& Morrison, K. (2007). Research Methods in Education Sixth edition: Routledge.

Çokluk, Ö., Şekercioğlu, G., ve Büyüköztürk, Ş. (2012). Sosyal bilimler için çok değiş̧kenli istatistik SPSS ve LISREL uygulamaları. Ankara: Pegem Akademi.

Danışman, Ş. ve Karadağ, E. (2019). Teaching ability beliefs scale: Adapting into Turkish and testing the construct validity. Çukurova Üniversitesi Ĕ̆itim Fakültesi Dergisi, 48(1), 577603.

Demir, M.K. (2013). İlköğretim bölümü öğretmen adaylarının epistemolojik inançlarının incelenmesi. Uludă̆ Üniversitesi Ĕ̆itim Fakültesi Dergisi 25(2), 343-358.

Demir, S. ve Akınoğlu, O. (2010). Epistemolojik inanışlar ve öğretme öğrenme süreçleri. Marmara Üniversitesi Atatürk Ĕ̆itim Fakültesi Ĕgitim Bilimleri Dergisi, 32, 75 - 93.

Doğanay, A. (2011). The Effect of pre-service teacher education on the educational philosophies of prospective teachers. Education and Science, 36(161), 332-348.

Ediger, M. (2000). Philosophy perspectives in teaching social studies. Journal of Instructional Psychology, 27(2), 112.

Febriyati, R.F. (2020). Teachers' beliefs on learner's autonomy of paragraph writing in society 4.0 in tenth graders of sman1 Nogosari. Unpublished PhD Thesis, The State Islamic Institute of Surakarta.

Fives, H., \& Buehl, M. M. (2012). Spring cleaning for the "messy" construct of teachers' beliefs: What are they? Which have been examined? What can they tell us? In K. R. Harris, S. Graham, T. Urdan, S. Graham, J. M. Royer, \& M. Zeidner (Eds.), APA handbooks in psychology®. APA educational psychology handbook, Vol. 2. Individual differences and cultural and contextual factors (p. 471-499). American Psychological Association. https://doi.org/10.1037/13274-019

Flanagan, J. C. (1952). The effectiveness of short methods for calculating correlation coefficients. Psychological Bulletin, 49(4), 342-348. https://doi.org/10.1037/h0057321

Gales, M. J. \& Yan, W. (2001). Relationship between Constructivist Teacher Beliefs and Instructional Practices to Students' Mathematical Achievement: Evidence from TIMMS. The Annual Meeting of the American Educational Research Association, Seattle, WA, (April 10-14, 2001).

Golombek, P.R. (1998). A Study of language teachers' personal practical knowledge. TESOL Quarterly, 32(3), 447-464.

Gürbüz, S. ve Şahin, F. (2018). Sosyal Bilimlerde Araştırma Yöntemleri (5.Bask1). Ankara: Seçkin Yayıncilık.

Hashweh, M.Z. (1996). Effects of science teachers' epistomological beliefs in teaching. Journal of Research in Science Teaching, 33(1), 47-63.

İslamoğlu, A. H. ve Alnıaçı, Ü. (2016). Sosyal bilimlerde araştırma yöntemleri: SPSS uygulamalı. İstanbul: Beta Yayıncılık. 
Jones, M.G., \& Carter, G. (2007). Science teacher attitudes and beliefs. In S. Abell \& N. Lederman (Eds.), Handbook of research on science education (1067-1104). Mahwah, NJ: Lawrence Erlbaum Associates.

Jolliffe, I. (2002). Principal Component Analysis. Springer. 2nd edition

Kagan, D.M. (1992). Implications of research on teacher belief. Educational Psychologist 27, 6590.

Kahramanoğlu, R. ve Özbakış, G. (2018). Sınıf öğretmenlerinin eğitim inançlarının ve epistemolojik inançlarının belirlenmesi ve aralarındaki ilişkinin incelenmesi. Disiplinlerarası Eğitim Araştırmaları Dergisi 2(3), 8-27.

Kotaman, H. (2008). Özyeterlilik inancı ve öğrenme performansının geliştirilmesine ilişkin yazın taraması. Uludă̆ Üniversitesi Ĕ̆itim Fakültesi Dergisi 11(1), 111-133.

Kuzborska, I. (2011). Links between teachers' beliefs and practices and research on reading Reading in a Foreign Language. 23(1), 102-128.

Levitt, K. (2002). An analysis of elementary teachers' beliefs regarding the teaching and learning of science. Science Education 86(1), 1-22.

Liu, M. (2003). Teachers' beliefs about issues in the implementation of a student-centered learning environment. Educational Technology Research and Development, 1(2), 57-76.

Love, A. (2002). The Relationship between teachers' beliefs and student achievement in two primarily african american urban elementary schools. The Annual Meeting of the American Educational Research Association, New Orleans, LA, (April 5, 2002).

Mansour, N. (2009). Science teachers' beliefs and practices: issues, implications and research agenda. International Journal of Environmental \& Science Education, 4(1), 25-48.

McNeill, K.L., Pimentel, D.S. \& Strauss, G.E. (2013). The Impact of high school science teachers' beliefs, curricular enactments and experience on student learning during an inquiry based urban ecology curriculum. International Journal of Science Education, 35(15), 2608-2644. doi:10.1080/09500693.2011.618193

Muijs, D. \& Reynolds, D. (2002). Teachers' beliefs and behaviors: what really matters? The Journal of Classroom Interaction, 37(2), 3-15.

Nespor, J. (1987). The role of beliefs in the practice of teaching. Journal of Curriculum Studies 19, 317-328.

Otrar, M. ve Argın, F. S. (2015). Öğrencilerin Sosyal Medyaya İlişkin Tutumlarını Belirlemeye Yönelik Bir Ölçek Geliştirme Çalışması. Eğitim ve Öğretim Araştırmaları Dergisi, Cilt 4, Say1 1(37).

Özdamar, K. (2016). Eğitim, să̆glk ve davranış bilimlerinde ölçek ve test geliştirme yapısal eşitlik modellemesi. Eskişehir: Nisan Kitabevi.

Özmen, K. S. (2012). Exploring student teachers' beliefs about language learning and teaching: A longitudinal study. Current Issues in Education, 15(1), 1-14. Retrieved from http://cie.asu.edu/ojs/index.php/cieatasu/article/view/819

Pallant, J. (2016). SPSS kullanma kılavuzu: SPSS ile adım adım veri analizi. Ankara: Anı Yayıncılık. 
Pedersen, S. \& Liu, M. (2003). Teachers' Beliefs about Issues in the Implementation of a Student-Centered Learning Environment. Educational Technology Research and Development, 51(2), 57-76.

Peyman, R., Gholam, R.K. \& Parviz, M. (2012). ESP in-service teacher training programs: Do they change Iranian teachers' beliefs, classroom practices and students' achievements? Ibérica, 24, 261-282.

Remillard, J.T. (2005). Examining key concepts in research on teachers' use of mathematics curricula. Review of Educational Research, 75(2), 211-246.

Rashidi, N. \& Mughadam, M. (2014). The Effect of teachers' beliefs and sense of self-efficacy on Iranian EFL learners' satisfaction and academic achievement. The Electronic Journal for English as a Second Language, 18(2), available online

Savaşçı-Açıkalın, F. (2009). Teacher beliefs and practice in science educatio. Asia-Pacific Forum on Science Learning and Teaching 10(1), 11-22.

Sah, F. M. \& Shah, P. M. (2020). Teachers' beliefs and practices in teaching listening. Creative Education, 11, 182-195. doi: $10.4236 /$ ce.2020.112013

Shafee, A. (2019). The Teaching of early reading in English using the phonics approach in Malaysian primary schools: Teacher beliefs, knowledge and practices. Unpublished PhD Thesis, Liverpool John Moores University.

Simmons, P.E., Emory, A., Carter, T., Coker, T., Finnegan, B., Crockett, D., Richardson, L., Yager, Y, Craven, J., Tillotson, J., Brunkorst, H., Twiest, M., Hossain, K., Gallagher, J., Duggan-Haas, D., Parker, J., Cajas, E, Alshannag, Q., McGlamery, S., Krockover, J., Adams, P., Spector, B., I.aPorta, T.James, B., Rearden, K., Lubuda, K. (1999). Beginning teachers: Beliefs and classroom actions, Journal of Research in Science Teaching 36(8), 930954.

Skott, J. (2013). Understanding the role of the teacher in emerging classroom practices: Searching for patterns of participation. ZDM-The International Journal of Mathematics Education, 45(4), 547-559. doi: 10.1007/s11858-013-0500-Z

Skott, J. (2015). The promises, problems, and prospects of research on teachers'beliefs. Science teacher attitudes and beliefs. In H.Fives \& M.G. Gill(Eds.), International handbook of research on teeachers' beliefs (13-30). Newyork, NY: Routledge.

Tam, A.C.F. (2015) The role of a professional learning community in teacher change: a perspective from beliefs and practices, Teachers and Teaching, 21(1), 22-43, doi: $\underline{10.1080 / 13540602.2014 .928122}$

Turan, M.B. (2019). The Relationship between university students' epistemological beliefs and teaching/learning conceptions. International Journal of Progressive Education, 15(1), 184194. doi: $10.29329 /$ ijpe.2019.184.12

Yıldiran, G. (2006). Multicultural applications of mastery learning: Our thoughts, our deeds and our hopes for education. İstanbul: Boğaziçi University.

Yıldırım, K., Çetinkaya, F.Ç. ve Ateş, S. (2016). Öğretmen adaylarının okuyucu inançları ve okuduğunu anlama başarıları arasındaki ilişkiler. Trakya Üniversitesi Sosyal Bilimler Dergisi 18(1), 299-314. 
EK:

\section{Öğrencilerin Başarısı ve Öğrenmesine Yönelik Öğretmen Görüşleri Ölçeği (ÖBÖY-ÖGÖ) Son Hali}

\begin{tabular}{|c|c|c|c|c|c|c|}
\hline \multicolumn{7}{|c|}{ Öğrencilerin Başarısı ve Öğrenmesine Yönelik Öğretmen Görüşleri Ölçeği } \\
\hline \multicolumn{7}{|c|}{$\begin{array}{l}\text { Değerli öğretmenimiz, Her yargıya vereceğiniz samimi ve içten cevaplar çalışmamıza değer } \\
\text { katacaktır. }\end{array}$} \\
\hline & 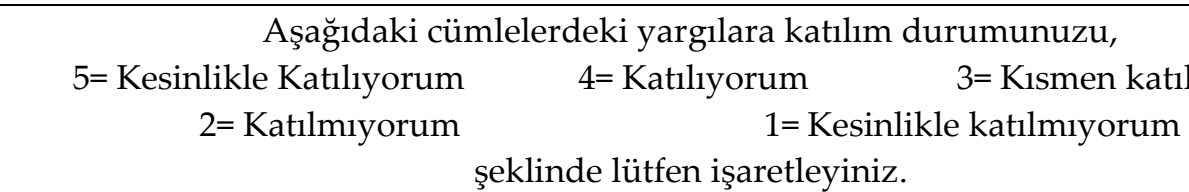 & yor & um & & & \\
\hline NO & & 5 & 4 & 3 & 2 & 1 \\
\hline 1 & $\begin{array}{l}\text { Öğrencinin öğrenmedeki başarısı doğuştan gelen, değişmez özelliklere } \\
\text { bağlldır. }\end{array}$ & & & & & \\
\hline 2 & Ancak zeki öğrenciler başarılı olur. & & & & & \\
\hline 3 & Yavaş öğrenenlerin hızlı öğrenenler kadar başarılı olma olasılı̆̆ı çok azdır. & & & & & \\
\hline 4 & Okuldaki başarı doğrudan öğrencinin zekâsıyla ilişkilidir. & & & & & \\
\hline 5 & $\begin{array}{l}\text { Daha az zeki öğrencilerin başarılı olması için okulun yapabilecekleri } \\
\text { sinırlıdır. }\end{array}$ & & & & & \\
\hline 6 & $\begin{array}{l}\text { Lise öğrencileri arasındaki öğrenme farklılıkları ortaokuldaki başarı } \\
\text { düzeyindeki farklılıklardan kaynaklanmaktadır. }\end{array}$ & & & & & \\
\hline 7 & $\begin{array}{l}\text { Ortaokul öğrencileri arasındaki öğrenme farklılıkları ilkokuldaki başarı } \\
\text { düzeylerindeki farklılıklardan kaynaklanmaktadır. }\end{array}$ & & & & & \\
\hline 8 & Okulda başarılı olan öğrencilerin özsaygısı daha yüksek olur. & & & & & \\
\hline 9 & $\begin{array}{l}\text { Başarılı öğrencilerin stresle başa çkabilme becerisi, başarısız öğrencilere } \\
\text { göre daha gelişmiştir. }\end{array}$ & & & & & \\
\hline 10 & Başarılı öğrencilerin özgüveni başarısız öğrencilerden yüksektir. & & & & & \\
\hline 11 & $\begin{array}{l}\text { Özgüveni yüksek olan öğrenciler, özgüveni düşük olan öğrencilerden daha } \\
\text { başarılı olurlar. }\end{array}$ & & & & & \\
\hline
\end{tabular}

